\title{
Correction to: Global experience with PSMA-based alpha therapy in prostate cancer
}

\author{
Mike M. Sathekge ${ }^{1,2} \cdot$ Frank Bruchertseifer $^{3} \cdot$ Mariza Vorster $^{1,2} \cdot$ Alfred Morgenstern $^{3} \cdot$ Ismaheel O. Lawal $^{1,2}$ \\ Published online: 17 August 2021 \\ ๑) Springer-Verlag GmbH Germany, part of Springer Nature 2021
}

\section{Correction to: Eur J Nucl Med Mol Imaging https://doi.org/10.1007/s00259-021-05434-9}

The authors request that they need to incorporate the below correction in their article in order to fully credit the original authors of the cited reference.

To replace the sentence:

"Figure 1 shows the nuclear recoil effect during $\alpha$-decay within radioligand for TAT."

With the sentence:

"Figure 1 from the paper by Roscher and colleagues shows the nuclear recoil effect during $\alpha$-decay within radioligand for TAT [37]."

The original article has been corrected.

Publisher's Note Springer Nature remains neutral with regard to jurisdictional claims in published maps and institutional affiliations.

The original article can be found online at https://doi.org/10.1007/ s00259-021-05434-9.

This article is part of the Topical Collection on Erratum.

Mike M. Sathekge

mike.sathekge@up.ac.za

1 Department of Nuclear Medicine, University of Pretoria \& Steve Biko Academic Hospital, Pretoria, South Africa

2 Nuclear Medicine Research Infrastructure, Pretoria, South Africa

3 European Commission, Joint Research Centre, Directorate for Nuclear Safety and Security, Karlsruhe, Germany 